\title{
Influência da maturação dos frutos na emergência e crescimento inicial de Copernicia hospita Mart. - Arecaceae ${ }^{1}$
}

\author{
Influence of fruit maturation on emergence and initial growth of Copernicia hospita \\ Mart. - Arecaceae
}

\author{
Diego de Sousa Pereira ${ }^{2 *}$, José Edilson Silva Sousa ${ }^{3}$, Magnum de Sousa Pereira ${ }^{4}$, Nayara Roberto Gonçalves ${ }^{5}$ e \\ Antonio Marcos Esmeraldo Bezerra ${ }^{6}$
}

\begin{abstract}
RESUMO - Objetivou-se nessa pesquisa avaliar a influência da maturação dos frutos na qualidade fisiológica das sementes e crescimento inicial de Copernicia hospita. Os tratamentos foram arranjados em um fatorial 2 × 3 x 2 com quatro repetições, os fatores foram constituídos por duas colorações de frutos (verde-amarelados e escuros), três tipos de propágulos (fruto íntegro, fruto despolpado e semente), e embebição (sem e com) por cinco dias, dispostos em um delineamento inteiramente casualisado. As variáveis de observação foram: porcentagem, velocidade e tempo médio de emergência, altura da planta, diâmetro do coleto, massa seca da parte aérea e do sistema radicular. Frutos de coloração escura, independentemente do tipo de propágulo, e frutos verdes amarelados despolpados, com ou sem embebição, mostram-se superiores com uma maior porcentagem de emergência, índice de velocidade e menor tempo médio de emergência. A embebição dos propágulos proporciona incrementos na massa seca da parte aérea, das raízes e no diâmetro do coleto.
\end{abstract}

Palavras-chave: Carnaubeira. Frutos-maturação. Sementes-qualidade.

\begin{abstract}
The objective of this research was to evaluate the influence of fruit maturation on the physiological quality of seeds and on initial growth of Copernicia hospita. Treatments were arranged into a 2 × 3 × 2 factorial, with four replications. The factors were made up of two fruit colourings (yellow-green and dark), three types of propagules (whole fruits, pulped fruits and seeds), and with and without soaking for five days and arranged in a completely randomized design. The observation variables were: percentage, speed and average emergence time; plant height; stem diameter; dry mass of the aerial part and root system. Dark colored fruits, regardless of the propagule type, and pulped yellow-green fruit, with or without soaking, are superior, having a higher percentage for emergence and speed index, and a lower average emergence time. Soaking the propagules increases the stem diameter and dry mass of the aerial part and the roots.
\end{abstract}

Key words: Carnaubeira. Fruits-maturation. Seed-quality.

\footnotetext{
*Autor para correspondência

${ }^{1}$ Recebido para publicação em 22/10/2012; aprovado em 24/09/2013

Pesquisa financiada pelo Conselho Nacional de Desenvolvimento Científico e Tecnológico

${ }^{2}$ Programa de Pós-Graduação em Agronomia-Fitotecnia, Laboratório de Analise de Sementes, Universidade Federal de Lavras, Campus Universitário, Caixa Postal 3.037, Lavras-MG, Brasil, 37.200-000, diegobizi@gmail.com

${ }^{3}$ Departamento de Fitotecnia, Universidade Federal do Ceará, Fortaleza-CE, Brasil, edilsonbieh@gmail.com

${ }_{4}^{4}$ Programa de Pós-Graduação em Solos e Nutrição de Plantas, Universidade Federal do Ceará, Fortaleza-CE, Brasil, magnum.ufc@gmail.com

${ }_{5}^{5}$ Programa de Pós-Graduação em Agronomia-Fitotecnia, Universidade de São Paulo-ESALQ, Piracicaba-SP, Brasil, nayararob1@ gmail.com

${ }^{6}$ Departamento de Fitotecnia, Universidade Federal do Ceará, Fortaleza-CE, Brasil, esmeraldo@ufc.br
} 


\section{INTRODUÇÃO}

Compreendendo um grupo de plantas com importância economia e ornamental, a família Arecaceae destaca-se nas regiões tropicais como fornecedora de cocos, tâmaras, palmito, açúcar, sagu, óleo, cera, fibras e material para a construção de habitações rústicas, como folhas e estipe, entre as espécies encontradas a carnaúba-hospedeira (Copernicia hospita Mart.), originária de Cuba, é uma palmeira solitária de 4 a $8 \mathrm{~m}$ de altura com folhas em forma de leque é considerada uma espécie rústica tolerante a solos úmidos. Possui inflorescências longas com frutos globosos, escuros, no final da maturação (LORENZI et al., 2004).

Apesar de essa espécie exótica apresentar características de interesse, não houve nenhum incentivo à sua exploração, e um dos motivos é a falta de estudos relacionados à propagação e melhoramento das espécies de palmeiras. Segundo Broschat (1994), a propagação de palmeiras é realizada principalmente por sementes, as quais apresentam limitações como germinação lenta, irregular e, frequentemente, em baixa porcentagem para a maioria das espécies de Arecaceae.

Para Iossi et al. (2007), o controle da qualidade de sementes é a base para uma maior produtividade em palmeiras. Essa qualidade deve ser monitorada em todas as fases do processo de produção, pois o desempenho da semente é resultado de transições desde a divisão celular até a quiescência, durante a maturação. Portanto, o momento ideal de colheita deveria ser aquele quando a semente atingisse a maturidade fisiológica, mas isto se torna difícil quando a espécie tem crescimento indeterminado ou apresenta dormência (CARVALHO; NAKAGAWA, 2000).

Nesse contexto, estudos científicos com a família Arecaceae vêm sendo desenvolvidos, destacando-se os trabalhos realizados com as espécies Archontophoenix cunninghamii H. Wendl. \& Drude (LUZ et al., 2011), Oenocarpus minor Mart. (OLIVEIRA et al., 2010), Phoenix canariensis hort. ex Chabaud (Pimenta et al., 2010), Butia capitata (Mart.) Becc. (NEVES et. al., 2010), Copernicia prunifera (Miller) H. E. Moore (REIS et al., 2010; REIS et al., 2011; SILVA et al., 2009), Copernicia hospita Martius (OLIVEIRA et al., 2009), Oenocarpus bacaba MART. (QUEIROZ; BIANCO, 2009), Rhapis excelsa (Thunberg) Henry ex. Rehder (LUZ et al., 2008), Syagrus romanzoffiana (Cham.) Glassman (BERNACCI et al., 2008), Phoenix roebelenii O'Brien (IOSSI et al., 2007), Euterpe edulis Mart. (MARTINS-CODER; SALDANHA, 2006), Astrocaryum aculeatum Meyer (FERREIRA; GENTIL, 2006; NAZÁRIO; FERREIRA; 2010), Thrinax parviflora Swartz. (PIVETTA et al., 2005).

Os autores relatam que para a produção de mudas de espécies de palmeiras é recomendada a remoção completa das partes do fruto que envolve as sementes, visando acelerar e uniformizar o processo germinativo; outro procedimento adotado é a imersão das sementes em água, como indicado para a espécie Copernicia prunifera (SILVA et al., 2009).

Apesar de serem sugeridas, para uma ampla variedade de espécies da família Arecaceae, a retirada do endocarpo e a imersão em água, para muitas espécies não há informações sobre os métodos a serem empregados, e suas consequências sobre as qualidades física e fisiológica dessas sementes. Diante das considerações, objetivou-se analisar a influência do estádio de maturação dos frutos na qualidade fisiológica das sementes e crescimento inicial de Copernicia hospita.

\section{MATERIAL E MÉTODOS}

Os propágulos utilizados no experimento foram colhidos em janeiro de 2010 de plantas-matrizes da espécie Copernicia hospita existentes na coleção da Fazenda Raposa, localizada no município de Maracanaú, estado do Ceará.

Após a coleta, os frutos foram acondicionados em embalagens permeáveis e transportados ao Laboratório de Análises de Sementes da Universidade Federal do Ceará, onde se determinou o teor de água dos propágulos, seguindo a metodologia prescrita nas Regras para Análise de Sementes (BRASIL, 2009).

Para obtenção dos propágulos foram selecionados frutos verde-amarelados $\mathrm{e}$ frutos escuros que não apresentavam ataque evidente de patógenos ou insetos. A polpa (epicarpo e mesocarpo) foi retirada utilizando-se uma faca de mesa. Para a retirada do endocarpo foi feito um pequeno corte superficial com um estilete e em seguida este foi facilmente removido, obtendo-se a semente.

Para avaliação dos tratamentos, instalou-se um experimento inteiramente casualizado em arranjo fatorial $2 \times 3 \times 2$ com quatro repetições de 50 propágulos, os fatores foram constituído por duas colorações de frutos (verde-amarelado e escuro), três tipos de propágulos (fruto íntegro, fruto despolpado e semente) e embebição em água por cinco dias (sem e com).

As parcelas foram dispostas em canteiros de $10 \mathrm{~m}^{2}$ contendo solo franco-arenoso no Núcleo de Ensino e Pesquisa em Agricultura Urbana do Departamento de Fitotecnia da Universidade Federal do Ceará. Cada repetição foi distribuída em duas fileiras de $1,0 \mathrm{~m}$ contendo 25 propágulos cada, mantendo-se um espaçamento de $0,20 \mathrm{~m}$ entre as fileiras. O suprimento de água na área do experimento foi realizado por meio de regas diárias, pela manhã e à tarde, por um sistema de microaspersão.

Aos 90 dias após a semeadura, avaliou-se a Porcentagem de emergência (PE) - realizada após contagem do número de plantas emergidas por repetições, 
com os resultados expressos em porcentagem; Índice de velocidade de emergência (IVE) - adaptando-se a metodologia proposta por Maguire (1962) após contagem diária do número de plantas emergidas; Tempo médio de emergência (TME) - adaptando-se a metodologia proposta por Labouriau (1983). Após a retirada do solo e lavagem das plantas em água corrente para limpeza das raízes avaliou-se com uma régua milimétrica a Altura da planta (ALT) e o Comprimento da raiz (CR); o Diâmetro do coleto (DC) foi mensurado com auxilio de um paquímetro digital com resolução de 0,001 mm; a Massa seca da parte aérea (MSPA) e a Massa seca das raízes (MSR) foram obtidas dividindo-se o peso obtido pelo número de plantas (g planta ${ }^{-1}$ ) após secagem dos respetivos órgãos em estufa com circulação de ar a $80{ }^{\circ} \mathrm{C}$ durante $24 \mathrm{~h}$.

Os dados de emergência e os parâmetros morfológicos, sem transformação, foram submetidos à análise de variância e as médias comparadas pelo teste de Tukey em nível de 5\% de probabilidade usando o aplicativo computacional SISVAR ${ }^{\circledR}$ (FERREIRA, 2003).

\section{RESULTADOS E DISCUSSÃO}

$\mathrm{Na}$ análise de variância apresentada na Tabela 1 observa-se a existência de interação entre a cor, o tipo de propágulo e a embebição (C x $\mathrm{P}$ x E) em cinco variáveis (PE, IVE, TME, ALT, CR) e interação entre propágulo e embebição ( $\mathrm{P}$ x E) em duas variáveis (MSPA, MSR). Não foi detectado nenhum tipo de interação no diâmetro do coleto sendo significativo apenas o efeito da embebição.

O despolpamento do fruto e a retirada da película que envolve a semente promoveram a redução do teor de água dos propágulos tanto nos frutos verde-amarelados quanto nos de coloração escura (Tabela 2). Com relação aos estádios de maturação dos frutos, os verde-amarelados, considerados imaturos, apresentaram maior teor de água do que os frutos escuros completamente maduros.

Para a porcentagem de emergência (Tabela 3) os frutos verde-amarelados íntegros que não foram pré-embebidos exibiram um percentual de emergência

Tabela 1 - Quadro resumo da análise de variância para a porcentagem de emergência (PE), índice de velocidade de emergência (IVE), tempo médio de emergência (TME), altura da parte aérea (ALT), comprimento da raiz (CR), diâmetro do coleto (DC), massa seca da parte aérea (MSPA), massa seca da raiz (MSR) dos diferentes tipos de propágulos de carnaúba obtidos 90 dias após a semeadura

\begin{tabular}{|c|c|c|c|c|c|c|c|c|c|}
\hline \multirow{2}{*}{ FV } & \multirow{2}{*}{ GL } & \multicolumn{8}{|c|}{--------------------------Valor e Significância do F--------------------------------- } \\
\hline & & $\mathrm{PE}$ & IVE & TME & ALT & $\mathrm{CR}$ & $\mathrm{DC}$ & MSPA & MSR \\
\hline Cor $(\mathrm{C})$ & 1 & $19,02 * *$ & $12,93 * *$ & $8,09 * *$ & $0,24^{\text {ns }}$ & $0,55^{\text {ns }}$ & $2,01^{\mathrm{ns}}$ & $2,63^{\mathrm{ns}}$ & $0,003^{\text {ns }}$ \\
\hline Propágulo (P) & 2 & $53,17 * *$ & $90,10 * *$ & $111,08 * *$ & $27,30 * *$ & $0,5^{\mathrm{ns}}$ & $0,3^{\mathrm{ns}}$ & $2,09^{\mathrm{ns}}$ & $3,53^{*}$ \\
\hline Embebição (E) & 1 & $4,11 \mathrm{~ns}$ & $0,03^{\text {ns }}$ & $42,31 * *$ & $0,01^{\mathrm{ns}}$ & $0,72^{\mathrm{ns}}$ & $9,18 * *$ & $10,40 * *$ & $0,73^{\mathrm{ns}}$ \\
\hline $\mathrm{C} \times \mathrm{P}$ & 2 & $6,14 * *$ & $6,25 * *$ & $0,43^{\text {ns }}$ & $0,08^{\text {ns }}$ & $0,95^{\mathrm{ns}}$ & $0,45^{\mathrm{ns}}$ & $4,18^{*}$ & $0,5^{\mathrm{ns}}$ \\
\hline $\mathrm{C} \times \mathrm{E}$ & 1 & $13,14 * *$ & $14,45^{* *}$ & $5,17 *$ & $1,01^{\mathrm{ns}}$ & $0,54^{\mathrm{ns}}$ & $0,11^{\mathrm{ns}}$ & $0,2^{\mathrm{ns}}$ & $5,12 * *$ \\
\hline $\mathrm{P} \times \mathrm{E}$ & 2 & $1,05^{\mathrm{ns}}$ & $2,02^{\mathrm{ns}}$ & $5,62 * *$ & $2,24^{\mathrm{ns}}$ & $0,12^{\text {ns }}$ & $3,14^{\mathrm{ns}}$ & $4,17 *$ & $5,65^{* *}$ \\
\hline $\mathrm{C} \times \mathrm{P} \times \mathrm{E}$ & 2 & $9,01 * *$ & $10,88^{* *}$ & $7,52 * *$ & $7,07 * *$ & $0,04 * *$ & $0,06^{\mathrm{ns}}$ & $0,54^{\mathrm{ns}}$ & $2,3^{\text {ns }}$ \\
\hline Resíduo & 36 & - & - & - & - & - & - & - & - \\
\hline $\mathrm{CV}(\%)$ & - & 13,07 & 10,88 & 7,52 & 7,07 & 12,81 & 20,33 & 32,73 & 32,73 \\
\hline
\end{tabular}

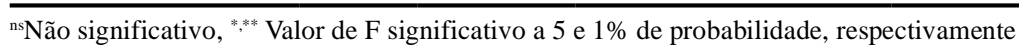

Tabela 2 - Valores médios do teor de água (\%) dos diferentes tipos de propágulos de Copernicia hospita

\begin{tabular}{lccc}
\hline \multirow{2}{*}{ Cor } & Propágulo & Sem & Com \\
\cline { 3 - 4 } Verde-amarelado & Íntegro & 52,07 & 62,87 \\
& Despolpado & 39,79 & 43,85 \\
& Semente & 41,31 & 47,53 \\
\hline \multirow{2}{*}{ Escuro } & Íntegro & 41,75 & 61,89 \\
& Despolpado & 37,06 & 45,09 \\
\hline
\end{tabular}


Tabela 3 - Média da variável porcentagem de emergência (PE), índice de velocidade de emergência (IVE), tempo médio de emergência (TME) e altura (ALT) de plantas oriundas dos diferentes tipos de propágulos de Copernicia hospita

\begin{tabular}{|c|c|c|c|c|c|}
\hline \multirow{3}{*}{ Cor } & \multirow{3}{*}{ Propágulo } & \multicolumn{4}{|c|}{------------------------------------Embebição------------------------------------ } \\
\hline & & Sem & Com & Sem & Com \\
\hline & & \multicolumn{2}{|c|}{ PE } & \multicolumn{2}{|c|}{ IVE } \\
\hline \multirow{3}{*}{ Verde-amarelado } & Íntegro & $60 \mathrm{aB}$ & $32 \mathrm{bC}$ & $0,45 \mathrm{aC}$ & $0,25 \mathrm{bC}$ \\
\hline & Despolpado & $93 \mathrm{aA}$ & $86 \mathrm{aA}$ & $0,83 \mathrm{aA}$ & $0,82 \mathrm{aA}$ \\
\hline & Semente & $68 \mathrm{aB}$ & $57 \mathrm{aB}$ & $0,64 \mathrm{aB}$ & $0,58 \mathrm{aB}$ \\
\hline \multirow{4}{*}{ Escuro } & Íntegro & $51 \mathrm{bB}$ & $75 \mathrm{aA}$ & $0,34 \mathrm{bB}$ & $0,64 \mathrm{aB}$ \\
\hline & Despolpado & $88 \mathrm{aA}$ & $88 \mathrm{aA}$ & $0,77 \mathrm{aA}$ & $0,82 \mathrm{aA}$ \\
\hline & Semente & $88 \mathrm{aA}$ & $77 \mathrm{aA}$ & $0,80 \mathrm{aA}$ & $0,73 \mathrm{aAB}$ \\
\hline & & \multicolumn{2}{|c|}{ TME } & \multicolumn{2}{|c|}{ ALT } \\
\hline \multirow{3}{*}{ Verde-amarelado } & Íntegro & $35,10 \mathrm{aA}$ & $33,44 \mathrm{aA}$ & $28,76 \mathrm{aA}$ & $24,00 \mathrm{bB}$ \\
\hline & Despolpado & $28,90 \mathrm{aB}$ & $27,22 \mathrm{aB}$ & $30,49 \mathrm{aA}$ & $32,41 \mathrm{aA}$ \\
\hline & Semente & $27,31 \mathrm{aB}$ & $24,83 \mathrm{bB}$ & $28,72 \mathrm{aA}$ & $29,73 \mathrm{aA}$ \\
\hline \multirow{3}{*}{ Escuro } & Íntegro & $39,82 \mathrm{aA}$ & $31,16 \mathrm{bA}$ & $25,91 \mathrm{aB}$ & $27,94 \mathrm{aB}$ \\
\hline & Despolpado & $30,03 \mathrm{aB}$ & $27,76 \mathrm{aB}$ & $31,20 \mathrm{aA}$ & $32,14 \mathrm{aA}$ \\
\hline & Semente & $28,52 \mathrm{aB}$ & $27,35 \mathrm{aB}$ & $30,03 \mathrm{aA}$ & $28,50 \mathrm{aB}$ \\
\hline
\end{tabular}

Médias seguidas de mesma letra, maiúsculas nas colunas e minúsculas nas linhas, não diferem entre si pelo teste de Tukey a $1 \%$ de probabilidade

superior aos embebidos, enquanto nos frutos escuros íntegros o comportamento foi inverso, qual seja, a pré-embebição ocasionou um acréscimo de $24 \%$ na percentagem de emergência.

A embebição dos propágulos provenientes dos frutos de coloração escura uniformizou a porcentagem de emergência situando-se os valores na faixa de 75-78\%, enquanto que nos frutos verde-amarelados os despolpados foram superiores às sementes e aos íntegros, os dados são conciliáveis aos observados por Oliveira et al. (2009), que observaram para a espécie Copernicia hospita uma variação nos valores médios de emergência de plântulas de 64 a $81 \%$ quando utilizadas sementes colhidas no estádio final de maturação, com frutos na coloração escura. O efeito benéfico da pré-embebição na uniformização da emergência de plântulas também foi observado por Silva et al. (2009) para a espécie Copernicia prunifera, com médias variando de 82 a $91 \%$ o que indica ser comum uma variabilidade entre as espécies de Copernicia.

Com relação à superioridade dos frutos escuros em promover melhores valores de emergência seria o resultado dos frutos encontrarem-se no final do processo de maturação. O mesmo efeito foi observado por Pimenta et al. (2010) em sementes de Phoenix canariensis e por Iossi et al. (2007) em sementes de Phoenix roebelenii, que apresentam maior qualidade fisiológica quando os frutos encontram-se na coloração marrom e preto-violáceo, respectivamente, ou seja, no estádio de maturação mais avançado.
As variáveis relacionadas ao vigor das plantas apresentaram padrão similar de variação no desdobramento do fator embebição dentro da combinação cor do fruto e tipo de propágulo. Verificaram-se comportamentos distintos do desdobramento citado apenas nos frutos verde-amarelados íntegros e escuros íntegros. A pré-embebição acelerou a emergência das plantas provenientes de frutos escuros íntegros.

A velocidade de emergência (Tabela 3) foi semelhante à percentagem de emergência no desdobramento da embebição dentro da combinação cor do fruto e tipo de propágulo, onde se verificou diferenças estatísticas, entre os níveis de embebição, apenas nos frutos verde-amarelado íntegro e escuro íntegro.

Oliveira et al. (2009) observaram para sementes de Copernicia hospita um menor intervalo entre os valores de velocidade de emergência, com valores de 0,37 a 0,48. O padrão foi observado por Silva et al. (2009), onde sementes pré-embebidas resultaram em valores de IVE variando de 0,27 a 0,53. Resultado semelhante foi obtido para Astrocaryum aculeatum, quando as sementes embebidas durante nove dias proporcionaram os maiores índices em relação às sementes não embebidas (FERREIRA; GENTIL, 2006).

A pré-embebição não aumentou o vigor das plantas originadas dos propágulos despolpados e sementes, tanto no verde-amarelado quanto no de coloração escura. Ainda na tabela 3 observa-se que as plantas produzidas 
a partir de frutos verde-amarelados despolpados foram mais vigorosas do que as originadas de frutos verdeamarelados íntegros e sementes, a despeito de sofrerem ou não embebição. Tal comportamento não foi verificado nas plantas provenientes dos propágulos de coloração escura.

Quanto ao tempo médio de emergência (Tabela 3) constata-se que a pré-embebição acelerou em 8,66 dias a emergência das plantas provenientes de frutos escuros íntegros. Os propágulos fruto despolpado e semente expressaram a máxima germinabilidade mais rápido do que o fruto íntegro nas duas colorações estudadas, tanto nos embebidos quanto nos não embebidos.

Para Copernicia hospita, Oliveira et al. (2009) observaram tempo médio de germinação semelhante aos obtidos neste ensaio, com valor médio de 33 dias. Silva et al. (2009) observaram para sementes de Copernicia prunifera um comportamento diferenciado, atingindo a máxima emergência aos 28 dias com a utilização de sementes pré-embebidas, sendo observado para sementes que não passaram pelo processo de pré-embebição valores de tempo médio de emergência da ordem de 60 dias.

Ferreira e Gentil (2006) ressaltam que para sementes de palmeiras o tempo médio de emergência é reduzido à medida que se eleva o período de pré-embebição, sugerindo-se que a retirada do endocarpo favoreça a redução desse período. Os autores observaram que a embebição das sementes de Astrocaryum aculeatum proporcionou menor tempo médio de emergência, emitindo o primeiro eófilo 187 dias após a semeadura, enquanto que em sementes secas, esse estádio foi observado aos 203 dias.

Analisando-se a altura da planta aos 90 dias (Tabela 3) observa-se que a pré-embebição dos frutos verdeamarelado íntegro reduziu em $4,76 \mathrm{~cm}$ o porte da planta enquanto nos demais desdobramentos da embebição dentro das outras combinações de cor do fruto e tipo de propágulo não foram constatados diferenças significativas.
A altura das plantas procedentes de propágulos originados de frutos verde-amarelados somente mostrou diferenças estatísticas quando os mesmos foram embebidos sendo as dos frutos verde-amarelados íntegros de menor altura do que as outras duas categorias.

O despolpamento e a extração das sementes de frutos de coloração escura originaram plantas mais vigorosas do que as procedentes de frutos íntegros, porém quando essas mesmas categorias foram submetidas à embebição as plantas produzidas a partir de frutos escuros despolpados foram as que se destacaram em relação aos outros dois tipos.

Observa-se que a pré-embebição dos frutos verde-amarelado íntegro reduziu em $4,76 \mathrm{~cm}$ o porte da planta. As plantas procedentes e propágulos originados de frutos verde-amarelados somente mostraram diferenças estatísticas para a altura quando os mesmos foram embebidos, sendo as dos frutos verde-amarelados íntegros menores do que as outras duas categorias. As plantas originadas de frutos de coloração escuros despolpados e sementes apresentaram maiores alturas do que as procedentes de frutos íntegros.

As médias do comprimento da raiz (Tabela 4) apresentaram diferenças significativas entre os frutos escuros íntegros embebidos em relação aos não embebidos. Nos demais desdobramentos não foram verificados diferenças estatísticas.

Examinando-se as médias do peso seco da parte aérea da planta (Tabela 5), verifica-se que no desdobramento da cor do fruto dentro do tipo de propágulo apenas no fruto íntegro houve diferença significativa, tendo o verde-amarelado íntegro exibido maior massa seca $\left(0,391 \mathrm{~g} \mathrm{planta}^{-1}\right)$ do que o preto íntegro $\left(0,279 \mathrm{~g}_{\text {planta }}{ }^{-1}\right)$. No estudo do tipo de propágulo em cada cor do fruto somente foram detectadas diferenças estatísticas na coloração escura, mesmo assim com resultados ambíguos.

Tabela 4 - Médias da variável comprimento de raiz (CR) de plantas oriundas dos diferentes tipos de propágulos de Copernicia hospita

\begin{tabular}{lccc}
\hline \multirow{2}{*}{ Cor } & & Sem & Com \\
\cline { 3 - 4 } & Propágulo & & CR \\
\cline { 3 - 4 } Verde amarelado & & $37,61 \mathrm{aA}$ & $35,45 \mathrm{aA}$ \\
& Íntegro & $32,53 \mathrm{aA}$ & $37,99 \mathrm{aA}$ \\
& Despolpado & $35,57 \mathrm{aA}$ & $33,30 \mathrm{aA}$ \\
\hline \multirow{3}{*}{ Escuro } & Semente & $32,44 \mathrm{bA}$ & $40,17 \mathrm{aA}$ \\
& Íntegro & $34,72 \mathrm{aA}$ & $33,32 \mathrm{aA}$ \\
\hline
\end{tabular}

Médias seguidas de mesma letra, maiúsculas nas colunas e minúsculas nas linhas, não diferem entre si pelo teste de Tukey a 5\% de probabilidade 
Tabela 5 - Médias da variável peso seco da parte aérea $\left(\mathrm{g}_{\text {planta }}{ }^{-1}\right)$ no estudo da interação cor do fruto e tipo de propágulo

\begin{tabular}{lccc}
\hline \multirow{2}{*}{ Cor } & Íntegro & Despolpado & Semente \\
\cline { 2 - 4 } & $0,391 \mathrm{aA}$ & $0,355 \mathrm{aA}$ & $0,312 \mathrm{aA}$ \\
Verde-amarelado & $0,279 \mathrm{bB}$ & $0,370 \mathrm{aA}$ & $0,314 \mathrm{abA}$ \\
\hline Escuro &
\end{tabular}

Médias seguidas de mesma letra, maiúsculas nas colunas e minúsculas nas linhas, não diferem entre si pelo teste de Tukey a 5\% de probabilidade

No estudo da interação entre tipo de propágulo e embebição ( $\mathrm{P}$ x E) para as massas secas da parte aérea e radicular, dados em grama por planta, notase que os frutos íntegros submetidos à embebição prévia originaram plantas mais robustas do que os não-embebidos. Estudando-se os propágulos dentro da embebição foram encontradas diferenças estatísticas apenas quando eles foram embebidos tanto no MSPA quanto MSR com uma tendência de superioridade dos íntegros em relação aos demais (Tabela 6).

Para as médias da massa seca da raiz na combinação dos fatores cor do fruto e embebição somente foram verificadas diferenças estatísticas para frutos escuros, no qual a embebição mostrou-se eficiente (Tabela 7).
Com relação ao vigor das plantas, os dados são semelhantes aos observados para Copernicia prunifera obtidos por Silva et al. (2009) e por Reis et al. (2011), para Copernicia hospita obtidos por Oliveira et al. (2009), para Astrocaryum aculeatum (FERREIRA; GENTIL, 2006; NAZÁRIO; FERREIRA, 2010), para Archontophoenix cunninghamii (Luz et al., 2011), sendo a pré-embebição das sementes fator favorável a um maior acúmulo de biomassa nas plântulas, sendo esta superioridade observada atribuída, conforme relata Silva et al. (2009), ao fato da embebição contribuir para o rápido processo de hidratação dos tecidos, possibilitando aumento da velocidade e uniformidade da emergência das plântulas, tornando-as capazes de suportar maiores variações de umidade e temperatura durante o desenvolvimento e crescimento inicial.

Tabela 6 - Médias da variável peso seco da parte aérea (MSPA) e peso seco da raiz (MSR) no estudo da interação entre tipo de propágulo e embebição

\begin{tabular}{|c|c|c|c|c|}
\hline & 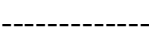 & 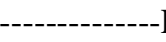 & -------------- & ------------ \\
\hline \multirow[t]{2}{*}{ Propágulo } & Sem & Com & Sem & Com \\
\hline & \multicolumn{2}{|c|}{ MSPA } & \multicolumn{2}{|c|}{ MSR } \\
\hline Íntegro & $0,264 \mathrm{bA}$ & $0,406 \mathrm{aA}$ & $0,081 \mathrm{bA}$ & $0,125 \mathrm{aA}$ \\
\hline Despolpado & $0,342 \mathrm{aA}$ & $0,382 \mathrm{aAB}$ & $0,081 \mathrm{aA}$ & $0,082 \mathrm{aB}$ \\
\hline Semente & $0,309 \mathrm{aA}$ & $0,317 \mathrm{aB}$ & $0,090 \mathrm{aA}$ & $0,066 \mathrm{aB}$ \\
\hline
\end{tabular}

Médias seguidas de mesma letra, maiúsculas nas colunas e minúsculas nas linhas, não diferem entre si pelo teste de Tukey a 5\% de probabilidade

Tabela 7 - Médias da variável massa seca da raiz (MSR) em grama por planta no estudo da interação entre a coloração dos frutos e a embebição

\begin{tabular}{lcc}
\hline & Ser & Com \\
\cline { 2 - 3 } & $0,093 \mathrm{aA}$ & $0,082 \mathrm{aA}$ \\
Verde amarelado & $0,075 \mathrm{bA}$ & $0,100 \mathrm{aA}$ \\
\hline
\end{tabular}

Médias seguidas de mesma letra, maiúsculas nas colunas e minúsculas nas linhas, não diferem entre si pelo teste de Tukey a 5\% de probabilidade 


\section{CONCLUSÕES}

1.Frutos de coloração escura, independentemente do tipo de propágulo, e frutos verdes amarelados despolpados, com ou sem embebição, mostram-se superiores com uma maior porcentagem de emergência, índice de velocidade e menor tempo médio de emergência;

2. A embebição dos propágulos proporciona um maior incremento na massa seca da parte aérea, das raízes e no diâmetro do coleto.

\section{REFERÊNCIAS}

BERNACCI, L. C. et al. Estrutura de estádios ontogenéticos em população nativa da palmeira Syagrus romanzoffiana (Cham.) Glassman (Arecaceae). Acta Botanica Brasilica, v. 22, n. 1, p. 119-130, 2008.

BRASIL. Ministério da Agricultura e Reforma Agrária. Regras para Análises de Sementes. Brasília: SNDA/ DNDV/CLAV, 2009. 399 p.

BROSCHAT, T. K. Palm seed propagation. Acta Horticulturae, v. 360, p. 141-147, 1994.

CARVALHO, N. M.; NAKAGAWA, J. Sementes: ciência, tecnologia e produção. 4. ed. Jaboticabal: FUNEP, 2000. 588 p.

FERREIRA. D. F. SISVAR - Sistemas de análises estatísticas. Lavras, UFLA. 2003.

FERREIRA, S. A. N.; GENTIL, D. F. O. Extração, embebição e germinação de sementes de tucumã (Astocaryum aculeatum). Acta Amazonica, v. 36, n. 2, p. 141-146, 2006.

IOSSI, E. et al. Maturação fisiológica de sementes de Phoenix roebelenii O'Brien. Revista Brasileira de Sementes, v. 29, n. 1, p. 147-154, 2007.

LABOURIAU, L. G. A germinação das sementes. Washington: OEA, 1983. 174 p.

LORENZI, H. Palmeiras brasileiras e exóticas cultivadas. Nova Odessa: Instituto Plantarum, 2004. 432 p.

LUZ, P. B. et al. Germinação de sementes de palmeiraráfia: efeito de tratamentos pré-germinativos. Revista Árvore, v. 32, n. 5, p. 793-798, 2008.
LUZ, P. B. et al. Germinação de sementes de palmeira-realaustraliana (Archontophoenix cunninghamii) sob efeito da imersão em água. Revista Agrarian, v. 4, n. 11, p. 27-32, 2011.

MARTINS-CORDER, M. P.; SALDANHA, C. W. Germinação de sementes e crescimento de plântulas de diferentes progênies de Euterpe edulis Mart. Revista Árvore, v. 30, n. 5, p. 693-699, 2006.

NAZÁRIO, P.; FERREIRA, S. A. N. Emergência de plântulas de Astrocaryum aculeatum G. May. em função da temperatura e do período de embebição das sementes. Acta Amazonica, v. 40 , n. 1 , p. $165-170,2010$.

NEVES, S. C. et al. Germinação in vitro de embriões de coquinho-azedo [Butia capitata (Mart.) Becc. (Arecaceae)] obtidos de frutos com diferentes graus de maturação. Revista de Biologia Neotropical, v. 7, n. 1, p. 47-54, 2010.

OLIVEIRA, A. B. et al. Emergência de plântulas de Copernicia hospita Martius em função do tamanho da semente, do substrato e ambiente. Revista Brasileira de Sementes, v. 31, n. 1, p. 281-287, 2009.

OLIVEIRA, A. B. et al. Aspectos anatômicos do embrião e desenvolvimento inicial de Oenocarpus minor Mart.: uma palmeira da Amazônia. Acta Botanica Brasilica, v. 24, n. 1, p. 20-24, 2010.

PIMENTA, R. S. et al. Efeito da maturação e temperatura na germinação de sementes de Phoenix canariensis hort. ex Chabaud - Arecaceae. Revista Árvore, v. 34, n. 1, p. 31-38, 2010.

PIVETTA, K.F.L. etal.Efeito da temperatura do armazenamento na germinação de sementes de Thrinax parviflora Swartz. (Arecaceae). Científica, v. 33, n. 2, p. 178-184, 2005.

QUEIROZ, M. S. M.; BIANCO, R. Morfologia e desenvolvimento germinativo de Oenocarpus bacaba Mart. (Arecaceae) da Amazônia ocidental. Revista Árvore, v. 33, n. 6, p. 1037-1042, 2009.

REIS, R. G. E. et al. Biometria e efeito da temperatura e tamanho das sementes na protrusão do pecíolo cotiledonar de carnaúba. Revista Ciência Agronômica, v. 41, n. 1, p. 81-86, 2010.

REIS, R. G. E. et al. Emergência e qualidade de mudas de Copernicia prunifera em função da embebição das sementes e sombreamento. Revista Caatinga, v. 24, n. 4, p. 43-49, 2011.

SILVA, F. D. B. et al. Pré-embebição e profundidade de semeadura na emergência de Copernicia prunifera (Miller) H. E. Moore. Revista Ciência Agronômica, v. 40, n. 2, p. 272-278, 2009. 